\title{
Stimulation of Erythrophagocytosis in Mouse Peritoneal Macrophages by Chondroitin Sulfates: Correlation with Effect of Phorbol Esters
}

\author{
Kozo Inaba*, Hitoshi Terada, and Toshio Shinoda \\ Biological Institute, Hyogo University of Teacher Education, 942-1 Shimokume, Yasiro-cho, Kato-gun, Hyogo \\ 673-14, Japan
}

Key words: phagocytosis/macrophages/chondroitin sulfates/phorbol esters

\begin{abstract}
$A B S T R A C T$. Resident macrophages which were harvested from the mouse peritoneal cavity showed the attachment activity to opsonized erythrocytes (OE) without the treatment of chondroitin sulfates (CSA) or phorbol esters. Phorbol ester (phorbol 12-myristate 13-acetate or phorbol 12,13-diacetate) rapidly activated an opsonin-dependent erythrophagocytosis in resident macrophages, whereas CSA slowly activated it in vivo and in vitro. An additive effect of phorbol esters was observed in macrophages which were cultured with CSA in vitro or stimulated by the intraperitoneal injection of CSA for 1 or 2 day(s). In the case of macrophages stimulated by the intraperitoneal injection of CSA for 3 or 4 days the erythrophagocytic activity was at very high level and the additive effect of phorbol esters vanished. These results indicate that CSA plays a role in the induction of opsonin-dependent ingestion activity of resident macrophages.
\end{abstract}

It is now clear that the phagocytic function of macrophages is a crucial element in the host defense system of vertebrates against a variety of invading microorganisms. In particular the mechanism of opsonin-dependent phagocytosis has been investigated extensively (16). Members of the stimulating substances of opsonin-dependent phagocytosis include bacterial lipopolysaccharides $(2,7)$, tumor-promoting phorbol esters (13) and fibronectin $(14,15)$. Insolubilised, surface-bound fibronectins (Fn) enhance opsonin-dependent phagocytosis of cultured human monocytes. Fn are complex dimeric adhesive glycoproteins (approximate MW 500,000 ) found in vertebrate plasm and in connective tissue matrices of certain embryonic and most wound healing tissues (5). We recently reported on a ubiquitous role of cytoskeleton systems in the intracellular transport of phagosomes following the ingestion of small or large latex beads in mouse peritoneal macrophages treated with chondroitin sulfates (11). Chondroitin sulfates are important components in the connective tissues of vertebrates, and show little toxicity and immunogenicity (10). In this paper we describe the correlation between the effect of chondroitin sulfates and that of phorbol esters on an opsonin-dependent phagocytosis by macrophages harvested from mouse peritoneal cavity.

\footnotetext{
* To whom correspondence and reprint requests should be addressed.
}

\section{MATERIAIS AND METHODS}

Macrophages. Resident macrophages were harvested from the peritoneal cavity of male mice (ddy strain). Cold Hank's solution ( $2.5 \mathrm{ml}$, Nissui Pharmaceutical Co. Ltd.) was injected into the peritoneal cavity of the mouse and the abdomen was then massaged for $30 \mathrm{sec}$. The ascitic fluid containing resident macrophages was harvested. The following experiments were carried out under sterile conditions. Usually macrophages in a $0.4 \mathrm{ml}$ portion were allowed to adhere to four pieces of round coverslip $(15 \mathrm{~mm}$ in diameter; Lux, Mile Laboratories, Inc., Naperville) which were placed in a tissue culture dish equipped with 4 wells (Nunc, Kamstrup) containing $1 \mathrm{ml}$ of RPMI-1640 medium (Nissui Pharmaceutical Co. Ltd, Tokyo) per well by incubating for $30 \mathrm{~min}$ at $37^{\circ} \mathrm{C}$. Contaminating cells other than macrophages were removed from the coverslip by washing several times with cold Hank's solution. Macrophages adhering to the coverslip were then incubated for $24 \mathrm{~h}$ at $37^{\circ} \mathrm{C}$ in the tissue culture dishes (Nunc) containing $1 \mathrm{ml}$ of RPMI-1640 medium supplemented with penicillin G (100 U/ml, Meiji Co. Ltd, Tokyo), streptomycin (100 $\mu \mathrm{g} / \mathrm{ml}$, Meiji Co. Ltd.), $10 \%$ bovine fetal serum (BFS) which was heat-inactivated $\left(56^{\circ} \mathrm{C}, 30 \mathrm{~min}\right)$, and $5 \mathrm{mM}$ tricine buffer (pH 7.3, Nakarai Chemicals, Ltd, Kyoto) per well. After washing sufficiently with cold Hank's solution, the macrophages ( 1 day cultures) adhered to the coverslip were used as experimental materials. Usually, the resident macrophages (1 day cultures) were additionally cultured with the RPMI-1640 medium in the presence or absence of $50 \mathrm{mg} / \mathrm{ml}$ chondroitin 
sulfates, type A (CSA, Sigma, St. Louis) for $24 \mathrm{~h}$ at $37^{\circ} \mathrm{C}$, and attachment and ingestion activities of these cells were assayed.

Peritoneal macrophages stimulated with CSA in vivo were also used in the experiment. The macrophages were harvested for 1 to 4 day(s) after intraperitoneal injection of $5 \%$ CSA ( $0.5 \mathrm{ml} / \mathrm{mouse})$, usually allowed to adhere to coverslip, and then washed sufficiently as described above before being used as experimental materials.

Phorbol esters. Phorbol-12-myristate-13-acetate (PMA) and phorbol-12,13-diacetate (PDA) were purchased from Sigma Chemical Company. Usually, resident macrophages (1 day cultures) adhered to coverslip were incubated with RPMI1640 medium containing $100 \mathrm{ng} / \mathrm{ml}$ of PMA at $37^{\circ} \mathrm{C}$ for 60 min and then erythrophagocytosis was estimated.

Erythrocytes. Blood was harvested from the carotid artery of chick at about a week old [white cornish (male) and white rock (female); Ross Breeders Ltd, London]. The blood was immediately diluted with about 10 volumes of cold PBS and centrifuged at $400 \times \mathrm{g}$ for $5 \mathrm{~min}$ at $4^{\circ} \mathrm{C}$. The washing treatment was repeated further 3 times and the erythrocytes were then suspended in RPMI-1640 medium to give a concentration of $10 \%$ (volume/volume).

Opsonization of the chick erythrocytes was carried out as follows. The chick erythrocyte suspension was added to RPMI-1640 medium containing 10\% mouse (ddy strain) serum to give a concentration of $1 \%$ (volume/volume), and incubated for $20 \mathrm{~min}$ at $37^{\circ} \mathrm{C}$. The erythrocyte suspension was then centrifuged at $400 \times \mathrm{g}$ for $5 \mathrm{~min}$ at $4^{\circ} \mathrm{C}$, and the precipitates (erythrocytes) were washed further 3 times with 100 volumes of cold RPMI-1640 medium. Finally, the erythrocytes were suspended with 50 volumes of RPMI-1640 medium containing $5 \mathrm{mM}$ tricine buffer ( $\mathrm{pH} 7.3$ ) and designated as $2 \%$ OE suspension. Concerning the character of opsonized erythrocytes, a natural (i.e. normal) anti-chick erythrocyte IgG was barely detectable, as were the complement 3 components (C3) on the erythrocytes, by immunofluorescence microscopy. The heat-inactivation of mouse serum (at $56^{\circ} \mathrm{C}$ for $30 \mathrm{~min}$ ) before the opsonization, or the elimination of $\mathrm{Mg}^{+2}$ which is essential for the activation of complements by the addition of EDTA to the opsonization process of chick erythrocytes, resulted in the failure of their attachment with mouse peritoneal macrophages.

Phagocytosis. In the estimation of opsonin-dependent attachment activity, macrophages adhering to coverslip were washed with cold Hank's solution and then incubated with BFS free RPMI- 1640 medium containing $5 \mathrm{mM}$ tricine buffer $(\mathrm{pH} 7.3$ ) and $\mathrm{OE}$ (final concentration of $0.2 \%$ ) for $45 \mathrm{~min}$ at $37^{\circ} \mathrm{C}$. After washing several times with Hank's solution, the macrophages adhering to coverslip were usually fixed with $2.5 \%$ glutaraldehyde- $0.18 \mathrm{M}$ cacodylate buffer ( $\mathrm{pH} 7.3$ ).

In the estimation of opsonin-dependent ingestion activity, macrophages adhering to coverslip were incubated for 120 $\min$ at $37^{\circ} \mathrm{C}$ in the same medium as used in the estimation of opsonin-dependent attachment activity. After incubation, non-ingested $O E$ were removed from macrophages by the hemolytic treatment (6) in $10 \mathrm{mM}$ ammonium chloride (pH 7.3). The macrophages were washed with Hank's solution and usually fixed with $2.5 \%$ glutaraldehyde- $0.18 \mathrm{M}$ cacodylate buffer (pH 7.3).

These coverslips were usually sealed, cell-side down, onto slides, and attached $\mathrm{OE}$ and ingested $\mathrm{OE}$ were quantitated by counting 300 cells per coverslip in three separate experiments via phase-contrast microscopy. The attachment activity was expressed as attachment rate and average number of attached OE per macrophage. The ingestion activity was expressed as phagocytic index, i.e. the percent of macrophages that ingested $\mathrm{OE}$ multiplied by the average number of ingested $\mathrm{OE}$ per macrophage.

\section{RESULTS}

It is well known that there are two processes, i.e. attachment and ingestion, in the phagocytosis of macrophages. Resident macrophages clearly showed the attachment activity of $\mathrm{OE}$ and there was no significant difference in attachment rate between the resident and CSA-stimulated macrophages (Table 1). There was, however, an increase in attached OE numbers per macrophage in the latter, which suggests that the phenomenon might be due to the increase in the surface area of macrophages after the stimulation of CSA.

It has been reported that phorbol esters stimulate the opsonin (C3)-dependent phagocytosis in cultured human monocytes (13). Similar effects of phorbol esters (PMA and PDA) on the erythrophagocytosis in resident macrophages harvested from the peritoneal cavity of normal mouse were observed. Figure 1 shows a time cource of activation of erythrophagocytosis by phorbol esters. When the resident macrophages (1 day cultures) adhering to coverslip were incubated with RPMI-1640 medium containing $100 \mathrm{ng} / \mathrm{ml}$ PMA or PDA before the assay for ingestion of $\mathrm{OE}$, the phagocytic activity increased with time in incubation up to $90 \mathrm{~min}$.

Figure 2 shows dose dependence of erythrophagocyto-

Table I. ATtaChMENT ACTIVITY OF PERITONEAL MACROPHAGES.

\begin{tabular}{|c|c|c|}
\hline & $\begin{array}{c}\text { Resident } \\
\text { macrophages }\end{array}$ & $\begin{array}{c}\text { Elicited } \\
\text { macrophages }\end{array}$ \\
\hline Attachment rate $(\%)^{\mathrm{c}}$ & $73 \pm 12$ & $89 \pm 7.0$ \\
\hline $\begin{array}{l}\text { Number of attached OE } \\
\text { per macrophage }\end{array}$ & $4.2 \pm 0.9$ & $8.3 \pm 1.1$ \\
\hline \multicolumn{3}{|c|}{$\begin{array}{l}\text { a Resident macrophages were harvested from the peritoneal cavity } \\
\text { of normal mouse } 3 \text { days after intraperitoneal injection of saline. } \\
\text { b Elicited macrophages were harvested } 3 \text { days after intraperitoneal } \\
\text { injection ( } 0.8 \mathrm{ml} / \text { mouse) of } 5 \% \text { CSA. } \\
\text { c Attachment rate was estimated } 30 \text { min after incubation and } \\
\text { expressed as mean and S.E. for } 6 \text { experiments. } \\
\text { d Numbers of attached OE per macrophage were expressed as } \\
\text { mean and S.E. for } 6 \text { experiments. }\end{array}$} \\
\hline
\end{tabular}




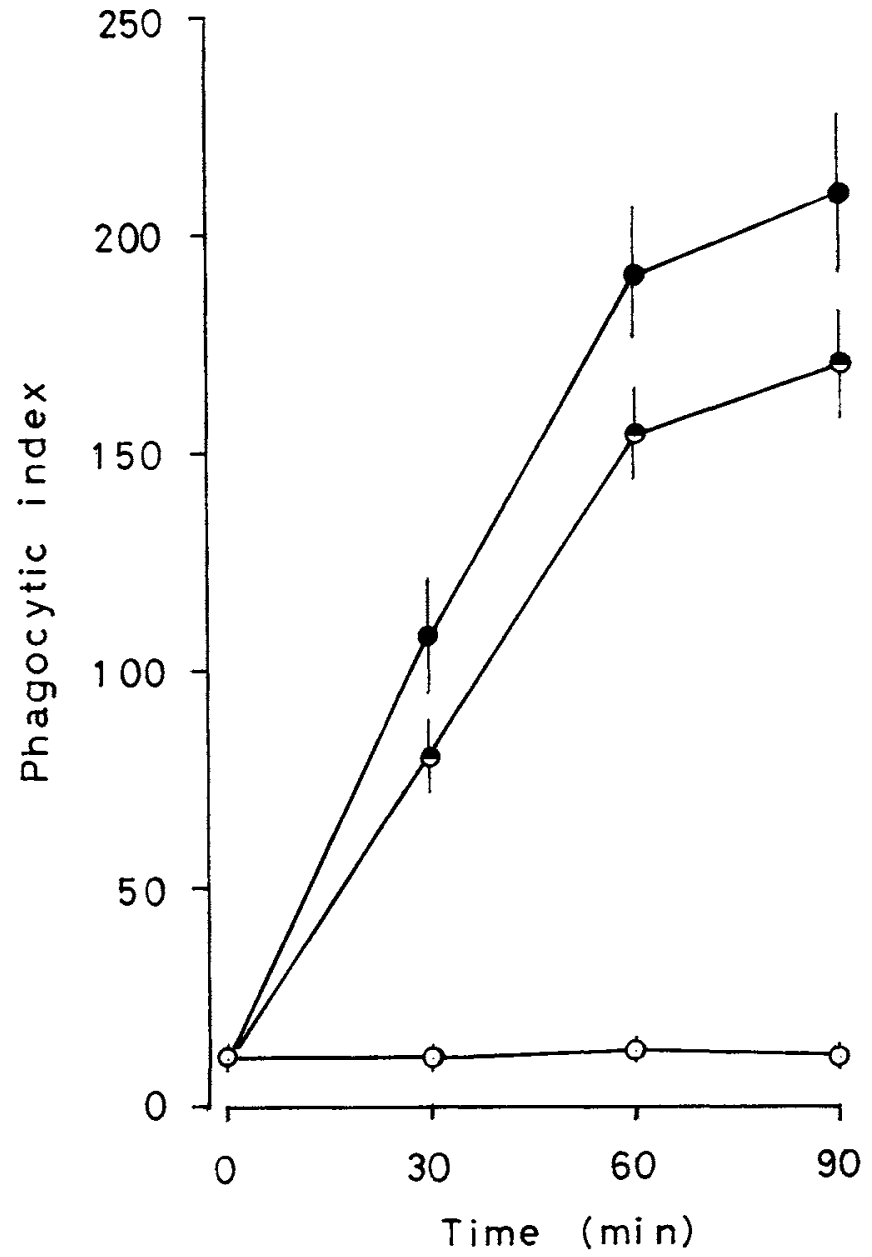

Fig. 1. Time course of activation of erythrophagocytosis by phorbol esters. Resident macrophages (1 day cultures) adhering to coverslip were incubatedd with RPMI-1640 medium containing 100 $\mathrm{ng} / \mathrm{ml}$ of PMA $(\bullet)$ or PDA $(\Theta)$ for the time indicated and phagocytosis of $O E$ was then estimated as described in Materials and Methods. Points represent the mean and S.E. for nine samples. Control, (O).

sis activation by PMA. On average, the erythrophagocytosis activation was significant at $10 \mathrm{ng} / \mathrm{ml}$ PMA concentration and further enhanced with increasing concentration up to $100 \mathrm{ng} / \mathrm{ml}$.

To estimate the effect of CSA on the opsonin-dependent phagocytosis of resident macrophages, the macrophages ( 1 day cultures) were additionally cultured in the presence or absence of CSA and the activity of erythrophagocytosis was assayed.

Figure 3 shows the time course of induction of erythrophagocytic activity by the culture of resident macrophages in the presence of CSA. The mean value of the phagocytic index clearly increased with time in culture up to $48 \mathrm{~h}$. The phagocytic index of macrophages cultured in the presence of CSA increased to about 13-fold the control $18 \mathrm{~h}$ after culture and to about 46 -fold the in-

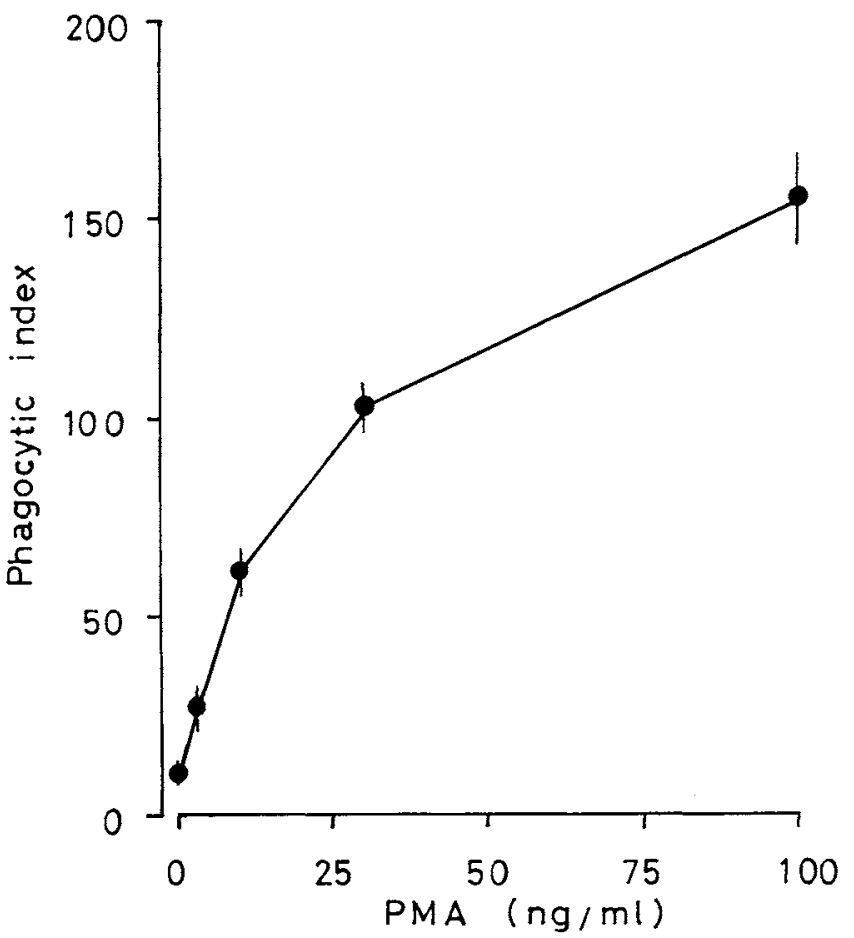

Fig. 2. Dose dependence of activation of erythrophagocytosis by PMA. Resident macrophages ( 1 day cultures) adhering to coverslip were incubated with RPMI-1640 medium in the presence or absence of increasing concentrations of PMA for $60 \mathrm{~min}$ and phagocytosis of OE was then estimated as described in Materials and Methods. Curve relates phagocytic index (P.I.) to PMA concentration during incubation. Points represent the mean and S.E. for four samples.

itial. These macrophages activated by CSA were barely able to phagocytize chick erythrocytes opsonized with mouse serum which was previously heat-inactivated at $56^{\circ} \mathrm{C}$ for $30 \mathrm{~min}$.

Under the same conditions, the dose dependence of CSA stimulation was estimated. Figure 4 shows the results of four such experiments. On average, the induction of erythrophagocytic activity was significant at 10 $\mathrm{mg} / \mathrm{ml} \mathrm{CSA}$ concentration and enhanced with increasing concentrations up to $60 \mathrm{mg} / \mathrm{ml}$. Under the same conditions, type $\mathrm{C}$ of chondroitin sulfates which were purchased from Sigma Chemical Company showed a stimulative effect on the erythrophagocytosis of resident macrophages but the extent of stimulation was lower than that of CSA (data not shown).

Table II shows the effect of PMA on OE ingestion of the resident macrophages which were cultured with RPMI-1640 medium in the presence or absence of CSA. The highest activity of erythrophagocytosis was observed in the resident macrophages which were cultured in the presence of CSA and incubated additionally with PMA.

Table III shows the effect of PMA on OE ingestion of 


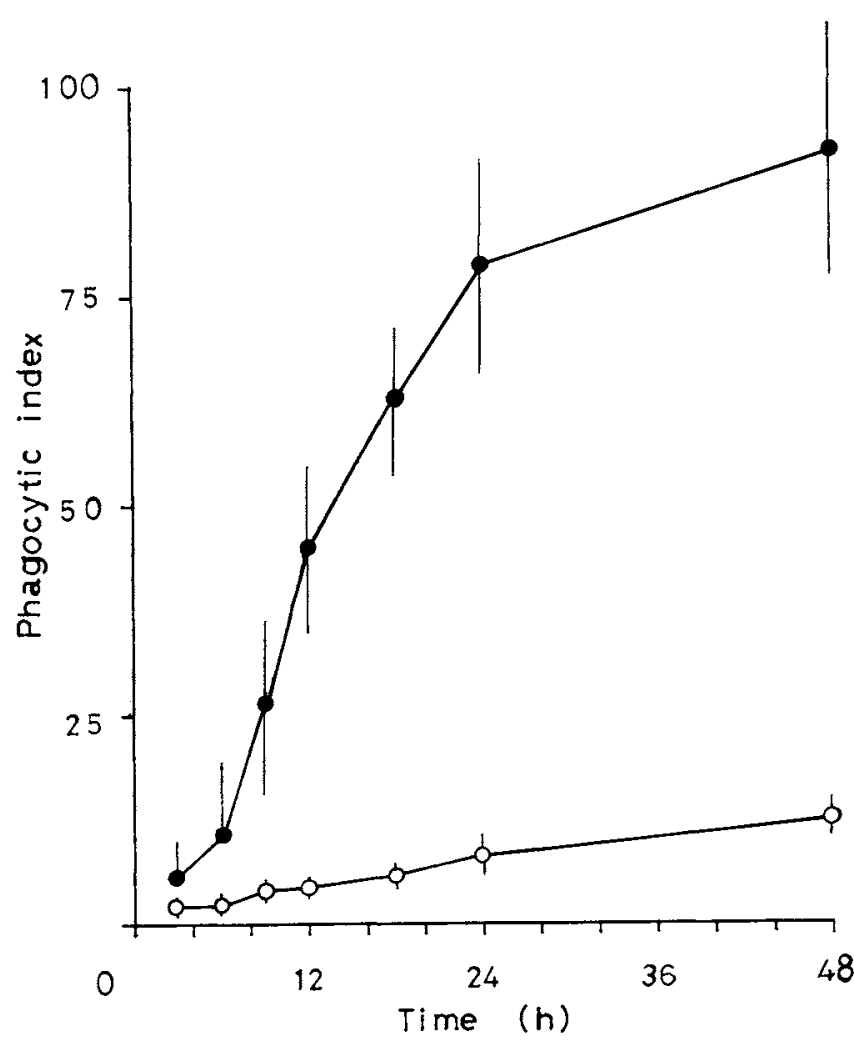

Fig. 3. Time course of induction of erythrophagocytic activity by CSA. Resident macrophages (1 day cultures) adhering to coverslip were cultured in RPMI-1640 medium supplemented with or without $50 \mathrm{mg} / \mathrm{ml} \mathrm{CSA}$. At time indicated, the monolayer was washed and the phagocytic activity of $\mathrm{OE}$ was then estimated as described in Materials and Methods. Curves relate P.I. to time of exposure of the cultures to CSA. Points represent the mean and S.E. for nine samples. Control (O), CSA $(\bullet)$.

macrophages stimulated by intraperitoneal injection $(0.5 \mathrm{ml} / \mathrm{mouse})$ of $5 \%$ CSA. An additive effect of PMA on the phagocytic activity of $\mathrm{OE}$ was significantly observed in the macrophages harvested 1 or 2 day(s) after the intraperitoneal injection of CSA. The additive effect of PMA vanished, however, in macrophages harvested 3 or 4 days after intraperitoneal injection of CSA and the macrophages showed high phagocytic activity of OE without the treatment of PMA.

\section{DISCUSSION}

These investigations present the first description of the stimulation of opsonin-dependent phagocytosis in mouse peritoneal macrophages by CSA in vivo and in vitro with correlation to the effect of phorbol esters. Phorbol esters enhanced the complement $(\mathrm{C} 3 \mathrm{~b}$ and $\mathrm{C} 3$ bi)-dependent erythrophagocytosis but not the antibody-dependent one in cultured human monocytes (13). The attachment activity of $\mathrm{OE}$ was clearly observa-

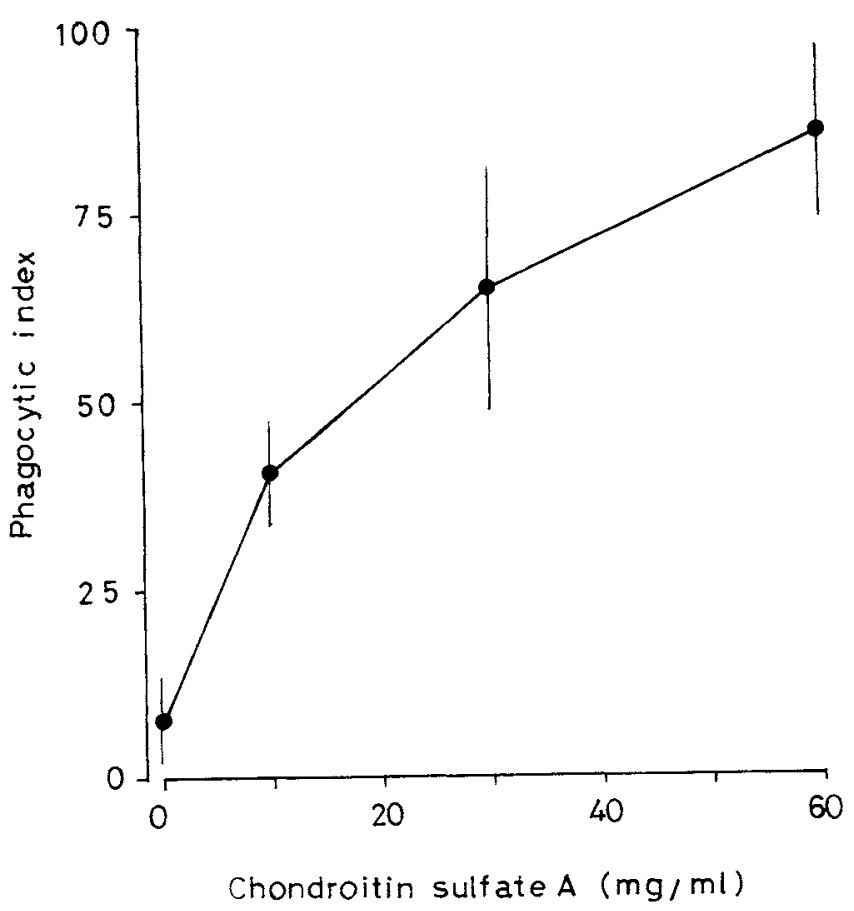

Fig. 4. Dose dependence of induction of erythrophagocytic activity by CSA. Resident macrophages ( 1 day cultures) adhering to coverslip were cultured for $24 \mathrm{~h}$ in the presence or absence of increasing concentrations of CSA. Cultures were washed and phagocytosis of OE was then estimated as described in Materials and Methods. Curve relates P.I. to CSA concentration during culture. Points represent the mean and S.E. for four samples.

Table II. EFFECT OF PMA ON THE ACTIVITY OF ERYTHROPHAGOCYTOSIS IN RESIDENT MACROPHAGES CULTURED IN THE PRESENCE OR ABSENCE OF CSA.

\begin{tabular}{cccc}
\hline \multirow{2}{*}{$\begin{array}{c}\text { CSA in culture } \\
\text { medium }^{\mathrm{a}}\end{array}$} & $\begin{array}{c}\text { Incubation } \\
\text { with PMA }\end{array}$ & \multicolumn{2}{c}{ Time in culture } \\
\cline { 3 - 4 } & & $24 \mathrm{~h}$ & $48 \mathrm{~h}$ \\
- & - & $7 \pm 3$ & $10 \pm 2$ \\
- & + & $137 \pm 18$ & $151 \pm 19$ \\
+ & - & $77 \pm 12$ & $91 \pm 16$ \\
+ & + & $181 \pm 21$ & $199 \pm 18$ \\
\hline
\end{tabular}

a CSA was added to give a concentration of $5 \%$ to RPMI-1640 medium.

b Macrophages adhering to coverslip were incubated with RPMI1640 medium containing PMA $(100 \mathrm{ng} / \mathrm{ml})$ for $60 \mathrm{~min}$ before incubation with $\mathrm{OE}$.

$c$ The mean and S.E. for 6 experiments.

ble in the resident macrophages and the stimulation of CSA scarcely affected the attachment rate of OE. The opsonin-dependent ingestion activity of the resident macrophage, however, was scarcely observed, i.e. the attachment signal of $\mathrm{OE}$ was scarcely coupled with the ingestion response. If resident macrophages were cultured in the presence of CSA or stimulated with the intraperitoneal injection of CSA, the signal-response 
Table III. EFFECT OF PMA ON THE ACTIVITY OF ERYTHROPHAGOCYTOSIS IN MACROPHAGES ELICITED BY INTRAPERITONEAL INJECTION OF CSA.

\begin{tabular}{lcccc}
\hline \multirow{2}{*}{ Treatments } & \multicolumn{4}{c}{ Days after intraperitoneal injection } \\
\cline { 2 - 5 } & 1 & 2 & 3 & 4 \\
\hline & \multicolumn{4}{c}{ Phagocytic index } \\
Control (saline) & $9 \pm 4$ & $23 \pm 5$ & $28 \pm 6$ & $32 \pm 6$ \\
CSA $^{\mathrm{b}}$ & $81 \pm 15$ & $120 \pm 19$ & $176 \pm 41$ & $222 \pm 39$ \\
CSA and incubation $_{\text {with PMA }}^{\mathrm{c}}$ & $116 \pm 18$ & $160 \pm 17$ & $193 \pm 19$ & $255 \pm 18$ \\
with
\end{tabular}

a Intraperitoneal injection of saline $(0.5 \mathrm{ml} / \mathrm{mouse})$.

b Intraperitoneal injection of $5 \% \mathrm{CSA}(0.5 \mathrm{ml} / \mathrm{mouse})$.

c Intraperitoneal injection of 5\% CSA and macrophages adhering to coverslip were incubated with $100 \mathrm{ng} / \mathrm{ml}$ PMA for $60 \mathrm{~min}$ before assay of erythrophagocytosis.

d The mean and S.E. for 6 experiments.

coupling functioned clearly without the addition of phorbol ester. In contrast to the immediate effect of phorbol ester, CSA slowly enhanced the opsonin-dependent ingestion activity. These results suggested that the incubation of resident macrophages with CSA induced activity in the opsonin-dependent phagocytic process which was correlated with the action of phorbol esters and probably connected with the coupling between the attachment signal of $\mathrm{OE}$ and ingestion response. This leads us to conclude that the attachment signal of $\mathrm{OE}$ could cause the activation of ingestion system in the macrophage without the addition of phorbol esters.

It has been reported that, when cells harvested from rat peritoneal exudate were incubated with chondroitin sulfate-Fe colloids, iron particles in the colloids were found specifically on the surface of macrophages but not on the surface of other peritoneal cells such as granulocytes, lymphocytes, mast cells and mesothelial cells histochemically and electron microscopically (8). Scavenger (or acetyl-LDL) receptors, which recognizes and binds sulfated glycosaminoglycans besides acetyllow density lipoproteins (acetyl-LDL) and negatively charged proteins modified chemically, occur on normal macrophages, and seems to lack exact domains $(1,9)$ or to be multifunctional. Scavenger receptors have been partially purified from a mouse macrophage cell line (P338) and confirmed as a protein of approximate relative molecular mass (Mr) 260,000 (12). Platelet granulederived factor 4 has been shown to be a chemotactic protein for human monocytes and neutrophils (3) and usually occurred in proteoglycan complexes containing chondroitin 4-sulfate (4). There is a hypothesis that the platelet-derived substance might serve as a chemotactic agent to attract blood monocytes to sites of tissue injury and to activate macrophages at these sites by interaction with the scavenger receptors (1). The results presented here support this hypothesis.

\section{REFERENCES}

1. Brown, M.S. and Goldstein, J.L. (1985). Scavenger cell receptor shared. Nature, 316: 680-681.

2. CoOper, P.H., Mayer, P., and BagGiolini, M. (1984). Stimulation of phagocytosis in bone marrow-derived mouse macrophages by bacterial lipopolysaccharide: correlation with biochemical and functional parameters. J. Immunol., 133: 913922.

3. Deuel, T.F., Senior, R.M., Chang, D., Griffin, G.L., Heinrikson, R.L., and Kaiser, E.T. (1981). Platelet factor 4 is chemotactic for neutrophils and monocytes. Proc. Nat. Acad. Sci. USA, 78: 4584-4587.

4. Huang, S.S., Huang, J.S., and Deuel, F. (1982). Proteoglycan carrier of platelet factor 4. J. Biol. Chem., 257: 1154611550.

5. Hynes, R.O. (1985). Molecular biology of fibronectin. Ann. Rev. Cell Biol., 1: 67-90.

6. Newman, S.L., Becker, S., and Halme, J. (1985). Phagocytosis by receptors for $\mathrm{C} 3 \mathrm{~b}\left(\mathrm{CR}_{1}\right), \mathrm{iC} 3 \mathrm{~b}\left(\mathrm{CR}_{3}\right)$, and $\mathrm{IgG}(\mathrm{Fc})$ on human peritoneal macrophages. J. Leukocyte Biol., 38: 267278.

7. Nowakowski, M., Edelson, P.J., and Bianco, C. (1980). Activation of $\mathrm{C} 3 \mathrm{H} / \mathrm{HeJ}$ macrophages by endotoxin. J. Immunol., 125: 2189-2194.

8. Ono, T. and Seno, S. (1986). Endocytosis of cationic and anionic iron colloid particles by rat macrophages. Acta Histochem. Cytochem., 19: 105-118.

9. Phillips, D.R., Arnol, K., and Innerarity, T.L. (1985). Platelet secretory products inhibit lipoprotein metabolism in macrophages. Nature, 316: 746-748.

10. Ruoslahti, E. (1988). Structure and biology of proteoglycans. Ann. Rev. Cell Biol., 4: 229-255.

11. Toyohara, A. and Inaba, K. (1989). Transport of phagosomes in mouse peritoneal macrophages. J. Cell Sci, 94: 143153.

12. Via, D.P., Dresel, H.A., Cheng, S., and Gotto, Jr. A.M. (1985). Murine macrophage tumors are a source of a 260,000dalton acetyl-low density lipoprotein receptor. J. Biol. Chem., 260: 7379-7386.

13. Wright, S.D. and Silverstein, S.C. (1982). Tumor-promoting phorbol esters stimulate $\mathrm{C} 3 \mathrm{~b}$ and $\mathrm{C}^{\prime} \mathrm{b}^{\prime}$ receptor-mediated phagocytosis in cultured human monocytes. J. Exp. Med., 156: $1149-1164$.

14. Wright, S.D., Craigmyle, L.S., and Silverstein, S.C. (1983). Fibronectin and serum amyloid P component stimulate $\mathrm{C} 3 \mathrm{~b}$ - and $\mathrm{C} 3 \mathrm{bi}$-mediated phagocytosis in cultured human monocytes. J. Exp. Med., 158: 1338-1343.

15. WRight, S.D., Licht, M.R., Lydia, S., Craigmyle, L.S., and Silverstein, S.C. (1984). Communication between receptors for different ligands on a single cell: Ligation of fibronectin receptors induces a reversible alteration in the function of complement receptors on cultured human monocytes. J. Cell Biol., 99: 336-339.

16. WRIGHT, S.D. and GRIFFIN, Jr. F.M. (1985). Activation of phagocytic cells' C3 receptors for phagocytosis. J. Leukocyte Biol., 38: 327-339.

(Received for publication, June 26, 1990 and in revised form, April 10, 1991) 